\title{
Weaving the Machine
}

\section{Enskilment as a Critical Aspect in the Design of Home Healthcare Technologies}

\author{
Kyle Kilbourn \\ Department of Industrial and Civil Engineering \\ University of Southern Denmark \\ Odense, Denmark \\ kki@ib.sdu.dk
}

\begin{abstract}
When hospital technologies migrate into the home environment, care shifts from 'self taken care of' to 'taking care of self'. As such, designing these tools is less about instantaneous usability and more about ongoing development of skill over time, especially when confronting the epidemic of chronic diseases. Research into what people do and how they act to manage their health through the combination of physical and immaterial technology becomes critical. Through a design anthropology approach, empirical findings show the work of learning technology for home dialysis requires a patient to become skilled in action and perception. This paper argues for interaction with healthcare technology that remains visible and tangible rather than disappearing into either the body or environment.
\end{abstract}

\section{Design anthropology; interaction design; skilled practice}

\section{INTRODUCTION}

The transition to home healthcare has been steadily gaining speed since the 1940s as new technologies enable patients and family members to participate in self-treatment at home [1]. Moving the treatment away from the hospital, or towards person-centered healthcare, creates challenges characterized as: "First patients are increasingly asked to become active users of health technology. Second, health technology is being unleashed from the hospital and introduced into a variety of "places" [2]. However, the field most dominant in the design of medieal products is the Human Factors profession, which dedicates itself to the use of technological products in an effort to make them easier to use [3]. This has be traced to scientific management before World War I, in which experimental psychologists conducted tests relating to aviation and the use of fighter planes through aero-medical laboratories [4].

One concern with employing human factors in medical technology, especially in the transition to the home, is that it downplays the developmental process of people and the influence of everyday life. Some guidelines suggest designers to 'dumb down' the product: "To assure the user's skill levels have been successfully addressed, the product should be designed to meet the capabilities of the least skilled potential user" [3]. In the constantly changing milieu of home healthcare, filled with tensions and meaning, utilizing a scientific management approach is hardly adequate. "People monitoring their own bodily functions or evacuating liquid waste from their peritoneal cavity can hardly be viewed as 'tasks', and analysed from a purely functional perspective" [2].

Permission to make digital or hard copies of all or part of this work for personal or classroom use is granted without fee provided that copies are not made or distributed for profit or commercial advantage and that copies bear this notice and the full citation on the first page. To copy otherwise, to republish, to post on servers or to redistribute to lists, requires prior specific permission and/or a fee. PERVASIVEHEALTH 2010, March 22-25, Munchen, Germany

Popyright @ 2010 ICST 978-963-9799-89-9

DOI 10.4108/ICST.PERVASIVEHEALTH2010.8789
Others have also questioned the position that bodies are selfcontained entities "What this suggests is that the assumption that we have a coherent body or are a whole hides a lot of work. This is work someone has to do. You do not have, you are not, a body-that-hangs-together, naturally, all by itself' [5].

The implication is that home healthcare is a practice and its success will come from revealing the work it takes to pull ourselves together in a world with leaky boundaries. For design to move beyond a focus on usability towards a growthorientated perspective, suggests a shift from the more dominate perspectives of either technology or medicine. Turner [6] proposed three ways of knowing a body (having a body, being a body and doing a body). Drawing upon and modifying this work produces perhaps harsher structure than the original, but clarifies the argument for the purposes of illustrating broad strokes between larger paradigms of thinking and its implications in the design of healthcare technology. There are three ways of knowing a body in healthcare: having a body through health and illness, being a body in the world, doing a body as skilled practice.

Having a body through health and illness can feel foreign and out of one's control when the medical gaze becomes the only way to detect conditions of the body [7]. This external view of the body also occurs when social meaning is attributed to a body in that "bodies speak, without necessarily talking, because they become coded with and as signs. They speak social codes" [8]. The enforcement of external and often "expert" perspectives traps bodies in a web of social control. This is the current paradigm when designing new healthcare technology, for example telemedicine projects that support healthcare professionals in only monitoring patients [9]. The second way of knowing a body, being a body in the world stands in contrast to the previous and derives from phenomenology and the philosophy of embodiment and has been popularized in the field of interaction design [10]. In using the concept of embodiment, the common strands between tangible and social computing research are brought together. However, this particular approach of embodied interaction creates principles with minimal capacity for guidance in designing as an activity. Being a body still implies a passive engagement with the world. There is another way to constrict the conceptual space that maintains the relational perspective between people and their environment while providing more details of how we engage with the world. 
The final way of knowing a body is the focus of this paper. Doing a body as skilled practice emphasizes the developmental aspect of skill in an environment, which contains other people and changes from one moment to the next. A person, from this perspective, is situated within a context or environment that allows for a particular practice or range of activities in which one's body is essential to the experience. Not only does this remove the external gaze of having a body but ties the body to the world through the growth of skill, embedded with the organism and the engaged world [11,12]. "Knowing" within this perspective does not rely on a disembodied mind moving a physical body, but rather sees actions as generating knowledge. The effect is a preservation of the relationship between perception and action, enabling the designing of tools for the skilled practitioner in self-health [13]. The perspective draws upon literature in fields of anthropology of skill [14] and ecological psychology [15].

\section{ThE ARTEFACTS OF TECHNOLOGY AND SKILL}

To make distinctions between people and their use of artifacts is to open up to a host of questions around what defines a person, a tool, a machine or technology. To insist on a separation between a user and tool only encourages and privileges the primacy of the mind to the exclusion of the body [16]. In this section, the "artefacts" of technology including the physical manifestations and consequences are explored from the philosophical and anthropological perspectives in order to define skill as the relation between people and the environment. In moving away from creating machines that separate knowledge from practice, the importance of tangibility in information technology is stressed in the development of new healthcare technology.

\section{A. We Are the Tools, or How Machines Separate Knowledge from Practice}

Clark [16] proposes that "There is no informationally constituted user relative to whom all the rest is just tools. It is [...] tools all the way down. We are just the complex, shifting agglomerations of "our own" inner and outer tools for thought. We are our own best artifacts, and always have been." The central argument from this perspective is that we as people are unique because our minds are tuned for creating mergers with the environment around us. As such, the equipment that we bring into operation define who we are, be it our physical apparatus (including our brains), or the technologies we create from pencils to computers. But what if the question is how can we design to access these inherent propensities for merging? We will find that distinctions do matter as our bodily resources have unique properties that we can put to use rather than default to over reliance on cognitive processing. In other words, the body is what matters, but not in isolation.

Medical professionals attend to the internal maintenance of our bodies. They prod, poke and measure in attempts to understand the biological underpinnings of our flesh. But one can also focus not just on the internal workings of the body, but in an altogether different sense, the body and the movements when patients use medical devices. Wainwright and Turner [17] propose that those in the field of medical humanities should rediscover Bourdieu's notion of "habitus" to help illustrate relationships between the body, self and society.
Their phenomenological view on the body is that it "has a material base that is shaped in a social context" [17]. By situating body movements as having relationships not only within our own bodies, but socially mediated and in relation to objects as well, we open up to a broader view of looking at patients, their bodies and their movements in connection to medical device use. However, we will need to explicate the differences between tools, machines and devices and the ongoing role of technology in creating these objects.

A common definition distinguishing a tool from a machine, at least in philosophy, is that characterized by [18]: "[T]he "tool" is a hand-operated machine or at least that element of direct contact between a machine and the world that in principle can be humanly manipulated, whereas "machine" denotes an instrument in its independence, or that aspect of an instrument that is not dependent on the human." In this way, the change from tools to machines was a significant transformation in that they are "no longer simply objects after the manner of hammers or saws; they have become containers for processes" [18]. These containers, in effect, become black boxes in which hidden processes lie out of sight. However, tool can also be defined in a quite different way, for example from an anthropologist's perspective: "A tool, in the most general sense, is an object that extends the capacity of an agent to operate within a given environment; an artefact is an object shaped to some pre-existent conception of form" [12]. While definition of "artefact" may seem to be analogous to the one for "machine" in that it has become a container for a process of a pre-existent conception from another person's mind, this would not take into account the critique leveraged against technology in the second definition. In fact, [12] sees technology as creating a division between practice and knowledge that ultimately does away with skill entirely.

\section{B. Skill as the Relation between People and Environment}

In dividing knowledge from practice, skill has become replaced by technology. Feibleman [19] offers an interesting contrast to this in which he says "Skills are often themselves the sources of technological progress. By doing, it is possible to learn how to do better, which is the way skills often suggest their own improvement." From this perspective, it is not that technology always severs the person from the environment: "Once a tool is made, a complex has been brought into existence, for man, the tool he uses, and the material object he uses it upon, are involved together in a single organization in which he plays an intermediate role. The skill serves to link him with the tool just as the tool serves to link him with the material object he wishes to change by its means" [19]. This is in line with [12] in that he sees the tool not just as "mere mechanical adjunct to the body, serving to deliver a set of commands issued to it by the mind; rather it extends the whole person" and even [16] when he proposes that our new technological tools will "start dovetailing back-when our technologies actively, automatically, and continually tailor themselves to us just as we do to them - then the line between tool and user becomes flimsy indeed." Perhaps the most wellknown advocate for these types of mergers comes from [20] and her advocacy for cyborgs in that "we are all chimeras, theorized and fabricated hybrids of machine and organism." The goal then is to reintegrate machines into the fabric of our 
interactions, to fuse through the means we have available to us-skills.

\section{Increasing Tangibility in Information Technology}

The way information technology is conceptualized to be "used" by people limits the range of possibilities that we employ when working with non-computerized objects, but as [10] contends the history of interaction design can be see as a "gradual expansion of the range of human skills and abilities that can be incorporated into interaction with computers." One of the early ideas for moving away from graphical and screen based interfaces is to be found in [21] with the goal to allow everyday spatial knowledge to serve as a way to interact with information technology. However, this project tried to force the graphical screen paradigm into the physical world. Continuing in a similar style is a strong research program as signified by [22] in Tangible User Interfaces in which the goal is to "give physical form to digital information."

Taking a stand against this "data-centered" view of tangible interaction, [23] have moved towards "perceptual-motor centered" tangible interaction. Not only does appearance act as a carrier of meaning, but they also see action as providing this ability. Instead of always relying on semantics, which use symbols and metaphors to give meaning, the direct approach uses feedback and feedforward (communicating the results of an action beforehand). While there is recently a body of work around tangibility in interaction design, there is not a strong connection to technique or skilled practice. Choosing to focus on the process of enskilment allows for another path in which to realize interaction with designed objects. Until now the overriding concept has been how to make what we design easier and usable. Bannon [24] exposed the paradox of designing for ease of learning as it results in the "decline of how to allow for the growth of competence and skill on many computer systems." Particularly in medical technology, the focus on skill has been left out in describing its use by patients.

There have been a few studies that look at patients' use of technology outside the medical setting and in places like the home. Lehoux et al. [2] shows how some patients take advantage of the technology to create a sense of autonomy from their disease by developing knowledge and skills in operating devices. They identify two attitudes towards technology as passive recipient or active user and suggest that not all patients ultimately come to depend upon technology for maintaining health. This redistribution of knowledge and skills is not simple and can meet with resistance depending on larger social aspects in which the technology is situated. Their study does not go into details about what skills the patients develop in their use of the technology. Additional studies around patient use of technology are needed.

As information technology becomes embedded within these devices, research into what people do and how they act to manage their health through this combination of physical and immaterial technology becomes critical. This section argues that health technology should remain visible and handy rather than disappearing into a cyborg body to allow us to become skilled in our use of technology.

\section{THE MOVEMENT FROM HOSPITAL TO HOME}

The empirical material collected in this section is based on observations and discussions as part of a research project exploring how patients become skilled in dealing with medical technology using a design anthropology approach. Such an approach insists upon a particular style of knowledge in which designerly ways of working are incorporated with inquiries into the possibilities of human ways of being [25]. Design anthropology is a study with rather than a study of people. What follows are a few vignettes from a particular medical speciality, home hemodialysis, in which patients learn to use a dialysis machine in a hospital in Denmark to cleanse their blood from impurities as the kidneys have slowed or fail to work at all. Fieldwork took place in the hospital as well as at the homes of several "patients" and the analysis included reviewing videotaped portions of the experience. The names have been changed.

\section{A. Viktor's Beeping Kidney}

It is his first day. It is the first time Viktor will be shown hemodialysis from the perspective as someone who will use the machine rather than the passive recipient tended to by healthcare professionals. Down the hall in a similar room in this hospital sits several dialysis machines for hooking up patients. But this room is different. There is a single dialysis machine. Yes, there is a nurse, but her role is different as well. The home dialysis department prepares these "patients" to move away from the hospital to do their medical care at home, without constant supervision. How is this possible? In what ways do patients turn into self-care practitioners?

The immediate work of dialysis, in a simplified and mechanical description, consists of three basic parts: setup, dialysis, and take down. During setup supplies like tubes, bottles of concentrate and filter are gathered and attached to the lower half of the device. The touch screen allows for starting the self-test of the system's functions and priming, and entering treatment time and volume removal. Needles are then inserted into the arm's access points and the pump is started. Dialysis has begun. Blood is removed from the arm, forced through a filter then returned to the same arm, although a different opening. During the cleaning, various alarms need to be attended to, which commonly include venous pressure and conductivity. When the allotted time or volume is complete, the pump is stopped. The tube connections are changed to allow for flushing fluid into the tube to reclaim any blood in the lines. The pump is restarted. When the tubes become clearer signifying that little blood remains, the needles removed to allow for closing up of the insertion site. Take down includes removal of the supplies from the device.

I focus on the first five days of this process in which the patient transitions to the practitioner. It is during this period that the nurse shows how to do dialysis from her point of view to Viktor clumsily placing the supplies on the machine and stumbling in the interface. Working from video recorded sequences of these first days, I compare similar points in time and expose the process for analysis. On the first day with Viktor, the nurse demonstrates the entire process while explaining what she is doing. The next time, she lets him attempt to setup the assorted apparatus of tubes, guiding when 
Viktor deviates or struggles. From there it progresses to gathering the necessary supplies from the cabinet and dealing with the alarms. It is not until several sessions later that patients like Viktor become confident inserting their own needles, calculating the multiple variables and progressing unassisted through the touch screen prompts.

\section{1) Placing the Bottle of Concentrate}

I will analyze a relatively simple and one of the first tasks, the placing of a bottle of concentrate into a clip at the bottom of the machine. As part of setting up, the bottle has to be placed by sliding up a lever. Then in a reverse action, push the clamp down to lock and puncture the bottle into place. The nurse with experience in this movement can quickly and without fuss accomplish this seemingly trivial step. On the first day of training, she starts by kneeling close to the floor and releases the clamp by pulling up to slide the lever on the bar. Then she guides the bottom of the bottle into the slot. Finally, the nurse stands slightly up and places her weight on the clamp using her right hand to force it down. On day two it is Viktor's turn to assemble the dialysis machine. He starts from a higher position and tries to insert the bottle by looking down. Viktor uses his right hand to hold the bottle and his left to work the clamp. However, there is resistance, as the bottle is not clamping into place. From this overhead position it is hard for Viktor to identify the problem. The nurse comes over to help and jiggles the clamp up and down to catch the ridge and snap it into position. By day three, Viktor tries a different strategy. Remembering the difficulty in getting the bottle to clamp down, he uses both hands to force the clamp down. But this also results in the nurse coming over to assist. She gets him to lift the clamp up again, first removing the dangling cords. She then mimics the clamping mechanism with her right hand. Day five is when Viktor is able to clamp the bottle into place without a nurse physically assisting. He starts from the standing and leaning over position using his right hand to insert the bottle and the left to attempt the clamping. Midway, he switches hand positions. So now his right hand is trying the clamp. Finally, he kneels down for a better view and clamps the bottle into place. Viktor is not as fluent in his actions as the nurse yet, but is moving from his initial exploration towards skilled performance through bodily attunement.

\section{2) Stringing the Tubes}

Another part of setup involves stringing the line of tubing in which the blood is pumped from the body into the filter and returned. A close coordination of perception and action is apparent when observing the steps Viktor takes to learn the pattern of how to lay out the tubes on the front of the dialysis machine. As before, the nurse shows the technique on the first day. She starts by pointing out the drip tube, which offers a reliable spot in which to begin. From there she clips the tube into the various catches before sliding the tube around the pump and finishes by connecting the remaining tubing. In day two the nurse gestures to the starting point so that Viktor knows where to begin. The tubing is packaged in a tight and neatly coiled bundle. Taking the tubes in his hands he attempts to lace the tubing through the clips. Because of the highly coiled nature of the tubing, it becomes difficult to distinguish the differences in the tubing. The nurse grabs part of the tubing from Viktor to untangle it and spread it out a bit. Viktor then tries to place the tube around the pump. As the pump spins around, it has an oblong shape. The nurse rotates the pump so that a gap is created to allow Viktor to insert the tube. By day five Viktor can easily identify the drip tube as the easiest starting point. He manages to wrap the tubing around the pump and also silences with the pump alarm, which starts beeping when he opens the pump door. At the end of the stringing process, Viktor even bends down for a better view and questions the nurse on the length of the pump tubing as being enough. One also has to remember the correct arrangement of the tubing. This remembering of the spatial layout is not only a property of a mental operation but also of body remembering. Remembering occurs when the body is in action, in this case while stringing the tubes. As [26] says "rhythm enlists the co-operation of a whole series of bodily motor reflexes in the work of remembrance."

\section{3) Dealing with Alarms}

Interacting with the touch screen plays an important role in silencing and addressing system alarms. One common call for action came from the conductivity alarm. In the first day, the nurse shows Viktor how to look up the list of alarms. For this particular alarm, she spins the bottle of concentrate, which was our focus previously. She then explains that air bubbles can be the cause of this type of alarm. On day three, Viktor has grasped that the first step in dealing with the alarm is to silence the annoying beep. The light continues to flash. He then taps against the bottle in the hopes of dislodging any air bubbles trapped. The alarm beeps loudly again. The nurse takes a turn at spinning the bottle around to see if that helps. By spinning the bottle on day one, the nurse allows for Viktor to mimic her actions in sequential days. The action that Viktor does is not identical to the spinning, rather it is a tapping or banging against the bottle. Action mimicking allows for a build up over time of the movement necessary as part of a skilled practice. In the guided movements of where to press the touch screen, inaccuracy is not tolerated. This very specific way of interaction does not leave much option for the budding practitioner to deviate and requires a very precise way of operating the machine. Ultimately, this precision contributes to the difficulty in learning over time.

\section{B. Learning Curves of Frederick's Practice}

Although we do not see Viktor progress beyond these first five days into a skilled practitioner, the threading of the machine might seem to be the most difficult part of the entire process in dialysis, yet complaints with the machine stem from working with the computer interface. Frederick, another person using the home dialysis machine, has become quite quick at stringing the tubes. As Frederick explains, "In the beginning, this is something, of course, you have to learn how to put it on and so on. I think I can do it faster than the nurse if I want to, because I know exactly how to do it." The physical setup, while a struggle at first, became part of the skilled practice of home dialysis. The touch screen interface continues to escape becoming part of the practice. Frederick says:

I would simply make the machine highlight that you are at step 1 now. Now you are at step 2, you need to go to step... It would help you to understand, okay, I am on step 4. It needs some kind of headline that tells you what to do. Or you can press on it and it will go detailed into what this step is about. Right now, you have to know it or look in the book, otherwise you are lost. There are some logical breaks. I don't know...a bad engineer? It took me two-three 
weeks to learn, it was so illogical, completely illogical. And I was not the only one who didn't get it. That one step is where you always got stuck. You couldn't remember how to continue.

Even by day five, the difference in learning the two interfaces is apparent. The bottom half with the multitude of physical connections is a struggle at first until bodily attunement and remembering contribute to a smoother operation. The top with the touch screen is quick to catch onto the one finger button press, but the changing locations and functionality ensures that one must concentrate on its operation for weeks to understand the quirks and rules built into the system. In essence, the dialysis machine has split the interaction into two nearly separate planes. I claim that this type of interface epitomizes the Cartesian split between body and mind. "Or organisms could be mechanized - reduced to body understood as resource of mind. These machine/organism relationships are obsolete, unnecessary," says [21].

In the beginning, the nurse lets the patient setup the machine, from the tubes and concentrates, to working the touch screen, dealing with alarms. Towards the end of the training they become more involved in the complicated action of inserting needles and calculating the amount of fluid to remove. A strong connection with bodily learning can be made in this particular case. For home dialysis, patients are an internal part of the hospital environment and learn to move outward to the home as part of the skilled practice. This move has consequences. As [27] says "moving toward full participation in practice involves not just a greater commitment of time, intensified effort, more and broader responsibilities within the community, and more difficult and risky tasks, but more significantly, an increasing sense of identity as a master practitioner." Developing a sense of identity as a practitioner becomes apparent when focusing on people within a social environment. Even patients can see themselves as a master practitioner as the highly skilled Frederick explains "I think I could tell some things, which a doctor can't tell you because I know exactly how it feels, what to do and what you can't do. [...] The doctor, if he tells you, it's only because he knows it from somebody."

Returning to Viktor and the bottle of concentrate, we see that over time he learned to perceive the bottle in multiple ways because of the events in which he participated with and used the bottle. As perception is intimately linked with action, perceptual learning can become a part of a practice of learning to perceive. While it may seem unusual to educate the attention of the visual perceptual system, [28] highlights how others outside of healthcare learn to perceive within their particular contexts through skilled vision. Thinking of situated bodily learning as "growing," allows one to intertwine skill with the structure of the body.

\section{Weaving the Machine}

While journeying into the skilled practice of the everyday, I have shown that the process of enskilment and its notion of situated bodily learning play a role in how people become skilled. But what should we make of our relations with the objects around us? A metaphor of weaving the machine stresses the entwining of tools and practice into the everyday, even to the point where the boundaries between body, tools and environment blur. But [29] describes what happens when the borders are too rigid: "The skilful skipper attends to his fishing technology as if it were an extension of his person; the novice, in contrast, focuses on the gear itself - fetishizing his gadgets, making more trips, and using more fuel, often destroying more gear in the process." In essence, tools become an extension of the body. However, machines, commonly seen as the encapsulation of technology, are implemented as autonomous things to operate without human intervention, a fetish to be worshipped because of the power of its creator.

We can proceed to characterize two ways of making connections between man and machines, rather heterogeneous elements. The first depends on a view of a person as a selfcontained capsule. Often espoused in the medical profession, the body is punctured in order to make a coupling between the inside and outside. This leads to looking at this link as a pipe of circulation, with one inherent weakness. There is usually a point of critical failure. Cut one line and the system is thrown into chaos. The touch screen on the dialysis machine exemplifies the interaction paradigm in that the task is limited within the mind. There is a single way to solve the problem presented: press here now (with one finger)! Each connecting piece has a standardized way of fitting together.

The alternative is viewing a person as one who makes relations between a meshwork of loose stitches, implying a changing system of joining. The robustness of the movement gives this view of interaction a likeness to the process of enskilment. Ingold [30] refers to it as a relation "not between one thing and another - between the organism 'here' and the environment 'there'. It is rather a trail along which life is lived: one strand in a tissue of trails that together make up the texture of the lifeworld." Exemplified in the stringing of the dialysis tubes, how one accomplishes the goal is suggested but not specifically defined. The skills of the practitioner allows for unique movements dependent on the person doing the "weaving." This openness is necessary in these types of relationships [31]: "Becoming, and openness to the future, and thus evolution, are unique properties of what is alive. [...] To think becoming, in the sphere of nature as much as in the sphere of technology, seems to me a crucial project for the future."

Beyond this simple dichotomy, how people weave machines into their lives can depend on the roles they choose or are forced to take as a relation is made with the designed artefact. In home dialysis, patients play out several roles: healthcare professionals by adjusting their own medication, custodial staff by cleaning and maintaining the dialysis machine, and purchasing staff by ordering new supplies to be delivered. Making the decision to adopt a technology means that it empowers patients to live longer, healthier lives but also bounds them to the machines. People often need to cope with the presence of a machine by transforming and incorporating them into a new practice. Frederick modified the machine by placing a screen cover to block out the glow during the night while he was trying to sleep as well as putting a holder on the screen for a medicine needed in the middle of setting up so as not to forget to inject it. To seriously contemplate how machines are woven into the physicality of the everyday 
requires a new stance of people from that which is prominent in interaction research. However, there are grave dangers of weaving the machine that cannot be ignored. This includes configuring the person. For home dialysis, it is the modification of sleeping habits. When one does overnight dialysis, one sleeps connected to the machine and must to stay still (to reduce the risk pulling out the needles) and refrain from bending one's arm (to minimize changes in blood pressure). Otherwise, the alarm will disturb one's sleep.

Currently, the way technologies are conceptualized to be "used" by people limits the range of possibilities that we commonly employ when working with non-computerized devices, objects and tools. Choosing to focus on the process of enskilment allows for another path in which to realize interaction with designed objects. Until now the overriding concept has been how to make what we design easier and usable. What are the consequences if we changed our perspective from designing for users to instead even see patients as skilled practitioners? For sure, the focus would move from usability towards how to design for enskilment. It is not to exclude usability as a goal, but rather to see it as a starting point in an active process of becoming and being skilled.

\section{CONCLUSION}

"Progress should mean growing competence in self-care rather than growing dependence" [32] and has for the last few decades been largely unheard. The conditions today, however, with the advances in information technology, reinvigorates the appeal for new tools. Technology is developed around the hospital and clinic with a partial concern for those directly effected by its consequences. The challenge remains: how to allow for self-care and growth. To get there, a change in thinking of patients as incapable and irresponsible is mandated. A call for tools that encourage enskilment will allow for the patient to be transformed into a skilled practitioner. Medical technology cannot move away from the hospital in its current form. The panopticon of medical surveillance will not be thought of too kindly in the home sphere. To rethink medical technology requires rethinking the idea of a patient. Patient is an unsustainable notion requiring an elite class of professionals overseeing an increasing number of dependents, whereas the patient as skilled practitioner selects among an array of options situated within his or her everyday environment, equipped with the necessary tools.

\section{REFERENCES}

[1] J.D. Arras and N.N. Dubler, "Introduction: Ethical and social implications of high-tech home care," Bringing the hospital home: Ethical and social implications of high-tech home care, J. Arras, H. Porterfield, and L. Porterfield, eds., Baltimore, Maryland: The Johns Hopkins University Press, 1995, pp. 1-31.

[2] P. Lehoux, J. Saint-Arnaud, and L. Richard, "The use of technology at home: what patient manuals say and sell vs. what patients face and fear," Sociology of Health \& Illness, vol. 26, 2004, pp. 617-44.

[3] R.C. Fries, "Human Factors Engineering," Handbook of Medical Device Design, R.C. Fries, ed., New York, New York: Marcel Dekker, 2001, pp. 353-394.

[4] D. Meister, "History of Human Factors in United States," International Encyclopedia of Ergonomics and Human Factors, K. Waldemar, ed., Florence, Kentucky: Taylor \& Francis, 2001, pp. 73-75.
[5] A. Mol and J. Law, "Embodied action, enacted bodies: the example of hypoglycaemia," Body and Society, vol. 10, 2004, pp. 43-62.

[6] B.S. Turner, Regulating bodies: Essays in medical sociology, London: Routledge, 1992.

[7] M. Foucault, Birth of the Clinic: An Archaeology of Medical Perception, New York, New York: Vintage Books, 1973.

[8] E. Grosz, Space, Time and Perversion, London: Routledge, 1995.

[9] H. Tap, "Nurses' methods and their relation to design," Occasional Papers from the Work Practice Laboratory, vol. 2, 2002, pp. 1-18.

[10] P. Dourish, Where the Action Is: The Foundations of Embodied Interaction, Cambridge, Massachusetts: The MIT Press, 2004.

[11] T. Ingold, "Beyond art and technology: The anthropology of skill," Anthropological perspectives on technology, M.B. Shiffer, ed., Alburquerque, New Mexico: University of New Mexico Press, 2001, pp. 17-31.

[12] T. Ingold, "Tool-use, sociality and intelligence," Tools, Language and Cognition in Human Evolution, T. Ingold and K. Gibson, eds., Cambridge: Cambridge University Press, 1993, pp. 429-472.

[13] K. Kilbourn and J. Buur, "The patient as skilled practitioner," Design Inquires, Stockholm, Sweden: 2007, pp. 89-99.

[14] T. Ingold, Perception of the Environment: Essays in Livelihood, Dwelling and Skill, Cambridge: Cambridge University Press, 2000.

[15] J.J. Gibson, The Ecological Approach to Visual Perception, Hillsdale, New Jersey: Lawrence Erlbaum Associates, 1979.

[16] A. Clark, Natural-Born Cyborgs: Minds, Technologies, and the Future of Human Intelligence, New York, New York: Oxford University Press, 2003.

[17] S.P. Wainwright and B.S. Turner, "Reflections on embodiment and vulnerability," Medical Humanities, vol. 29, Jun. 2003, pp. 4-7.

[18] C. Mitcham, Thinking through Technology: The Path between Engineering and Philosophy, Chicago, Illinois: University of Chicago Press, 1994.

[19] J.K. Feibleman, "Technology as skills," Technology and culture, vol. 7, 1966, pp. 318-328

[20] D. Haraway, "A Cyborg Manifesto: Science, Technology and SocialistFeminism in the Late 20th Century," Simians, Cyborgs and Women: The Reinvention of Nature, New: Routledge, 1991, pp. 149-181.

[21] G.W. Fitzmaurice, "Graspable User Interfaces," PhD Dissertation, University of Toronto, 1996.

[22] B. Ullmer, H. Ishii, and R.J.K. Jacob, "Token+constraint systems for tangible interaction with digital information," ACM Trans. Comput.Hum. Interact., vol. 12, 2005, pp. 81-118.

[23] T. Djajadiningrat, S. Wensveen, J. Frens, and K. Overbeeke, "Tangible products: redressing the balance between appearance and action," Personal Ubiquitous Comput., vol. 8, 2004, pp. 294-309.

[24] L. Bannon, "From human factors to human actors: The role of psychology and human-computer interaction studies in system design," Design at Work: Cooperative Design of Computer Systems, J. Greenbaum and M. Kyng, eds., Hillsdale, New Jersey: Lawrence Erlbaum, 1991, pp. 25-44.

[25] Kilbourn, Kyle, "The patient as skilled practitioner: A design anthropology approach to enskilment in health and technology," Unpublished PhD Dissertation, University of Southern Denmark, 2008.

[26] P. Connerton, How societies remember, Cambridge: Cambridge University Press, 2004 [1989].

[27] L. Lave and E. Wenger, Situated learning: legitimate peripheral participation, Cambridge: Cambridge University Press, 1991.

[28] C. Grasseni, ed., Skilled Visions: Between Apprenticeship and Standards, New York, New York: Berghahn Books, 2006.

[29] G. Pálsson, "Enskilment at sea," Man, New Series, vol. 29, 1994, pp. 901-927.

[30] T. Ingold, "Rethinking the animate, re-animating thought," Ethnos, vol. 71, 2006, pp. 9 - 20.

[31] E. Grosz, Architecture from the Outside: Essays on Virtual and Real Space, Cambridge, Massachusetts: MIT Press, 2001.

[32] I. Illich, Limits to Medicine, London: Marion Boyars Publishers, 1976. 